Article

\title{
Characterisation of SARS-CoV-2 Lentiviral Pseudotypes and Correlation between Pseudotype-Based Neutralisation Assays and Live Virus-Based Micro Neutralisation Assays
}

\author{
Inesa Hyseni ${ }^{1}$ (D), Eleonora Molesti ${ }^{1, *}$, Linda Benincasa ${ }^{1}$, Pietro Piu ${ }^{2}$ (D), Elisa Casa ${ }^{1,2}$, \\ Nigel J Temperton ${ }^{3}$ D , Alessandro Manenti ${ }^{1,2}$ and Emanuele Montomoli ${ }^{1,2,4}$ \\ 1 VisMederi Research s.r.l., 53100 Siena, Italy; hyseni@vismederiresearch.com (I.H.); \\ linda.benincasa@vismederiresearch.com (L.B.); casa@vismederiresearch.com (E.C.); \\ alessandro.manenti@vismederiresearch.com (A.M.); montomoli@unisi.it (E.M.) \\ 2 VisMederi s.r.l., 53100 Siena, Italy; pietro.piu@vismederi.com \\ 3 Viral Pseudotype Unit, Medway School of Pharmacy, The Universities of Kent and Greenwich at Medway, \\ Chatham ME7 4TB, UK; n.temperton@kent.ac.uk \\ 4 Department of Molecular and Developmental Medicine, University of Siena, 53100 Siena, Italy \\ * Correspondence: eleonora.molesti@vismederiresearch.com
}

Received: 23 July 2020; Accepted: 6 September 2020; Published: 10 September 2020

check for updates

\begin{abstract}
The recent outbreak of a novel Coronavirus (SARS-CoV-2) and its rapid spread across the continents has generated an urgent need for assays to detect the neutralising activity of human sera or human monoclonal antibodies against SARS-CoV-2 spike protein and to evaluate the serological immunity in humans. Since the accessibility of live virus microneutralisation (MN) assays with SARS-CoV-2 is limited and requires enhanced bio-containment, the approach based on "pseudotyping" can be considered a useful complement to other serological assays. After fully characterising lentiviral pseudotypes bearing the SARS-CoV-2 spike protein, we employed them in pseudotype-based neutralisation assays in order to profile the neutralising activity of human serum samples from an Italian sero-epidemiological study. The results obtained with pseudotype-based neutralisation assays mirrored those obtained when the same panel of sera was tested against the wild type virus, showing an evident convergence of the pseudotype-based neutralisation and MN results. The overall results lead to the conclusion that the pseudotype-based neutralisation assay is a valid alternative to using the wild-type strain, and although this system needs to be optimised and standardised, it can not only complement the classical serological methods, but also allows serological assessments to be made when other methods cannot be employed, especially in a human pandemic context.
\end{abstract}

Keywords: SARS-CoV-2; wild type virus; lentiviral pseudotypes; biosafety; microneutralisation; serological assays

\section{Introduction}

In early December 2019, cases of severe pneumonia of unknown aetiology were reported by the China Health Authority. In January 2020, a novel coronavirus was identified as 2019-nCoV (subsequently renamed as SARS-CoV-2).

An initial site of infections was the Huanan seafood market, where live animals are sold. Progressively, human-to-human transmission occurred [1], causing a disease named coronavirus disease 2019 (COVID-19). On 20th July 2020, the World Health Organization (WHO) estimated the global incidence of COVID-19 as 14,348,858 cases and the number of the deaths as 603,691 [2]. 
SARS-CoV-2 is a member of the Coronaviridae family, which comprises two subfamilies of enveloped, positive-stranded RNA viruses. The subfamilies of Coronavirinae are classified in four genera: alpha-CoV, beta-CoV, gamma-CoV and delta-CoV [3].

Genome sequence analysis has shown that SARS-CoV-2 belongs to the Betacoronavirus genus, which includes BatSARS-like coronavirus, Severe Acute Respiratory Syndrome coronavirus (SARS-CoV) and Middle Eastern Respiratory Syndrome coronavirus (MERS-CoV) [4].

The SARS-CoV-2 genome contains four main structural proteins: the spike (S), membrane (M), envelope (E) and nucleocapsid $(\mathrm{N})$ protein $[5,6]$.

The spike (S) protein of coronaviruses, a type I membrane glycoprotein expressed on the viral surface, mediates the attachment of SARS-CoV-2 to the target cells and its subsequently entry. As previously shown in the case of SARS-CoV $[7,8]$, the SARS-CoV-2 S protein engages angiotensin-converting enzyme 2 (ACE2) as its host target receptor. ACE2 is the main host cell receptor of SARS-CoV-2 and plays a crucial role in the entry of the virus into the cells [9].

In addition, viral entry requires $S$ protein priming by cellular proteases, such as the serine protease TMPRSS2, which allows the fusion of viral and cellular membranes to fuse [10,11]. As a result, the spike is cleaved into two subunits: the N-terminal domain, called S1, which is responsible for receptor binding [12-15], and a C-terminal S2 domain, which is responsible for fusion [14,15].

As the coronavirus $\mathrm{S}$ glycoprotein is surface-exposed and mediates entry into host cells, it is the main target of neutralising antibodies (Abs) [16] upon infection, and therefore, the focus of therapeutic strategies and vaccine design.

However, since SARS-CoV-2 displays marked pathogenicity (COVID-19) [17], working with the live virus (LV) implies the need for high biosafety levels laboratories (BSL3). By contrast, the lentiviral pseudotypes system, which has already been successfully adopted in the fight against emerging and re-emerging viruses, constitutes a useful, safe and versatile tool for studies on potential vaccines and therapies. Indeed, the lentiviral pseudotype platform can be efficiently used in conventional biosafety conditions to study cell type susceptibility on the bases of the cell's expression of ACE2 and protease priming [18-20]. Moreover, pseudotypes bearing the spike S-protein of the novel SARS-CoV-2 could prove essential for antibody detection and for the evaluation of neutralisation activity in association with the well-characterised serological methods, such as the Enzyme-linked immunoassay (ELISA) and Micro-Neutralisation assay (MN) [21-23].

In the present study, we described the production and characterisation of lentiviral pseudotype particles bearing the SARS-CoV-2 S protein and used these to study S-protein-mediated cell entry. Subsequently, SARS-CoV-2 pseudotypes were also used to measure neutralising antibody responses in serum samples derived from a subset of subjects involved in a sero-epidemiological study in the Tuscany region of Italy during the 2019 outbreak and a panel of negative confirmed sera.

The results were compared with the data obtained when the SARS-CoV-2 live virus was tested in the MN assay.

\section{Materials and Methods}

\subsection{Cell Line Cultures}

HEK 293 T/17 cells (Human embryonic kidney 293 cells) (ATCC-CRL 1573), MDCK cells (Madin-Darby Canine Kidney cells) (ATCC ${ }^{\circledR}$ CCL-34), Vero E6 cells (Epithelial cell line from the kidney of a normal monkey Cercopithecus aethiops) (ATCC-CRL 1586) and Caco2 cells (epithelial cell line from Human Colorectal Adenocarcinoma) (ATCC HTB37) were acquired from the American Type Culture Collection.

Huh-7 cells (Epithelial cell line from Human hepatocellular carcinoma) (ECACC—Code 01042712) and Hep G2 cells (Human Caucasian hepatocyte carcinoma) were provided by the University of Siena, Italy. 
Hep G2 cells were cultured in RPMI 1640 (Gibco) supplemented with 2 mM L-Glutamine (Lonza, Milan, Italy), 100 units/mL penicillin-streptomycin (Lonza, Milano, Italy) and $10 \%$ foetal bovine serum (FBS) (Euroclone, Pero, Italy).

HEK293 T/17, MDCK and Huh-7 cell lines were cultured in Dulbecco's Modified Eagle's Medium (DMEM) High Glucose (Euroclone, Pero, Italy) supplemented with $2 \mathrm{mM}$ L-Glutamine (Lonza, Milan, Italy), 100 units/mL penicillin-streptomycin (Lonza, Milan, Italy) and 10\% of FBS (FBS Euroclone, Pero, Italy).

Vero E6 and Caco2 cells were cultured in Eagle's Minimum Essential Medium (EMEM) (Lonza, Milan, Italy) supplemented with $2 \mathrm{mM}$ L-Glutamine (Lonza, Milan, Italy), 100 units/mL penicillin-streptomycin (Lonza, Milan, Italy) and FBS (Euroclone, Pero, Italy) to a final concentration of $10 \%$ for Vero E6 and 20\% for Caco2.

All the cell lines used were incubated at $37{ }^{\circ} \mathrm{C}, 5 \% \mathrm{CO}_{2}$ in humidified atmosphere and were sub-cultured twice a week until passage 20.

\subsection{Serum Samples}

A total of 65 samples from an Italian sero-epidemiological study, anonymously collected in compliance with Italian ethics law, were provided by the laboratory of Molecular Epidemiology of the University of Siena, Italy. The human sera, derived from a sero-epidemiological study, had previously been tested in an ELISA assay as pre-screening, and positive, borderline and negative ELISA samples were tested in a micro-neutralisation assay, as previously described [24]. This panel of sera was subsequently tested with SARS-CoV-2 pseudotypes in order to compare the neutralisation profiles when they were tested against the live virus and the surrogate virus. As an internal positive control, a panel of samples collected from health care workers (confirmed positive for SARS-CoV-2 by Reverse Real-Time PCR) were kindly provided by Prof. Valentina Bollati, University of Milan.

In addition, three monoclonal antibodies (mAbs) were included in the serological assay: Human IgG1 anti-S1 CR3022 (Native Antigen, Oxford, UK), Human IgG1 Anti-RBD (eEnzyme, Gaithersburg, MD, USA) and Human Anti-IgM SARS-CoV-2 spike S1 CR3022 (Absolute Antibody, 21 Drydock Avenue, 7th Floor Boston, MA 02210, USA (1:100 starting dilutions).

\subsection{Production, Quantification and Characterisation of Lentiviral Pseudotypes with S Protein from SARS-CoV-2}

\subsubsection{Plasmids}

The full-length S protein (GenBank accession number: YP_009724390.1) was codon-optimised and synthesised (GenScript, Cina), and the $\mathrm{S}$ fragment was cloned into the expression vector as described previously [25]. The HIV gag-pol plasmid (p8.91) [26], the firefly luciferase-expressing plasmid (PCSFLW) [27], the pCAGGS-TMPRSS2 plasmid and the plasmid encoding for the spike's human ACE2 receptor were kindly provided by Dr. Nigel Temperton and have previously been described [28-30].

As a control, a vesicular stomatitis virus (VSV-G) plasmid was used (pCMV-VSV-G) (Addgene plasmid 8454; http://n2t.net/addgene:8454) [31]. The day before transfection, confluent plates of HEK 293T/17 cells were split 1:4 and seeded into $10 \mathrm{~cm}^{2}$ plates in DMEM $10 \%$ FBS.

Cells (at the $60 \%$ of confluence) were co-transfected with the S plasmid from SARS-CoV-2 $(2 \mathrm{ug} / \mathrm{uL})$, HIV gag-pol $(1 \mathrm{ug} / \mathrm{uL})$ and the pCSFLW $(1.5 \mathrm{ug} / \mathrm{uL})$ using EndoFectin ${ }^{\mathrm{TM}}$ Lenti transfection reagent (Tebu Bio-217EF002, Via Pretorio 4-C.P. 70. I-20013 Magenta, Milano) in accordance with the manufacturer's instructions.

The following day, the supernatants were replaced with DMEM without phenol red (Thermo Fisher Scientific, 168 3rd Ave, Waltham, MA 02451, United States containing 10\% FBS, and the plates were incubated for $48 \mathrm{~h}$ at $37^{\circ} \mathrm{C}$ in an atmosphere of $5 \% \mathrm{CO}_{2}$. After $48 \mathrm{~h}$, the supernatants of transfected cells were harvested and filtered by Millex-HA 0.45 um filter. 
Concurrently, HEK 293T/17 cells were also transfected with VSV-G plasmid $(1 \mu \mathrm{g} / \mu \mathrm{L})$, and a no-spike control ( $\Delta$ envelope) was generated by co-transfection with HIV gag-pol and pCSFLW plasmids only.

\subsubsection{SARS-CoV-2 Pseudotypes Titration}

For SARS-CoV-2 titration, a further transfection is required in order to allow pseudotypes to enter target cells.

The day before titration, HEK 293T/17 cells were co-transfected with two plasmids encoding for the ACE2 receptor gene and TMPRSS2, by means of EndoFectin ${ }^{\mathrm{TM}}$ Lenti transfection reagent; after overnight incubation at $37^{\circ} \mathrm{C}$, the supernatant was replaced by DMEM containing $10 \%$ FBS.

The following day, supernatants were serially two-fold diluted in a fresh cell culture medium in 96-well, flat-bottomed culture plates, and $1 \times 10^{4}$ HEK 293T/17 target cells were added to each well. As controls, VSV-G and $\Delta$-envelope pseudotypes were also included. After $72 \mathrm{~h}$, the luminescence of cell cultures (in Relative Luminescence Units or RLUs) was evaluated by luminometry (Tecan Infinite M1000 Pro Multi-Detection Plate Reader) using the Bright-Glo assay system (Bright-Glo ${ }^{\mathrm{TM}}$ Luciferase Assay System, Promega, Viale Piero e Alberto Pirelli, 6, 20126 Milano MI).

\section{4. $p 24$ Capsid ELISA}

Serial dilutions of SARS-CoV-2 pseudotype-containing media were tested by means of the Lenti-X p24 Rapid titre kit (Cat. No. 632200) (Takara, Japan) in accordance with the manufacturer's instructions.

\subsection{Western Blotting}

In order to verify the incorporation of the S glycoprotein of SARS-CoV-2, the S protein expressed on the lentiviral pseudotypes was detected by Western blot analysis.

Western blot analysis of spike protein was performed on the supernatant from sub-confluent HEK 293T/17 cells co-transfected with HIV gag-pol plasmid, CSFLW plasmid and the S plasmid from SARS-CoV-2. Western blot analysis was also performed on LV in a BSL3 facility.

$\Delta$-envelope (no-spike control) pseudotypes prepared with the same procedure were run as a negative control. SARS-CoV-2 pseudotypes, SARS-CoV-2 live virus and $\Delta$-envelope pseudotypes were mixed with SDS sample buffer. The mixture was heated for $10 \mathrm{~min}$ at $75^{\circ} \mathrm{C}$ and electrophoresis $(50 \mu \mathrm{g}$ of protein/sample) was carried out in 4-12\% Bis-Tris Gels (Life Technologies, Carlsbad, CA, USA). Proteins were then blotted onto nitrocellulose membranes and incubated overnight with 500-fold diluted sera from convalescent SARS-CoV-2 patients. A Goat Anti-human IgG (Bethyl, 25043 FM 1097, Montgomery, TX 77356, United States) was used as a secondary antibody (1:5000 dilution). The chemiluminescent signals from the nitrocellulose membranes were captured by a camera system (ImageQuant LAS 400 instrument).

\subsection{SARS-CoV-2 Pseudotypes Tropism Study}

In this study, different cell lines have been tested in order to study their susceptibility to SARS-CoV-2 $S$ protein driven entry, the role of the ACE2 receptor and TMPSSRS2 for S protein priming.

One day before pseudotypes titration, MDCK, Vero E6, Caco2, Hep G2 and Huh7 cells were transfected with the pCAGGS-TMPRSS2 plasmid, while HEK 293T/17 cells were co-transfected with ACE2 and pCAGGS-TMPRSS2 plasmids. After $24 \mathrm{~h}$, the cells were removed by trypsinisation, counted and used for the subsequent titration.

In parallel with SARS-CoV-2 pseudotypes, VSV-G and $\Delta$-envelope pseudotypes were titrated as controls. Plates were incubated for $48-72 \mathrm{~h}$ with the pseudotypes, at $37^{\circ} \mathrm{C}$ in an atmosphere of $5 \% \mathrm{CO} 2$, and the efficiency of pseudotypes entry was characterised on the basis of luciferase activity (Relative Luminescence Units or RLUs). 


\subsection{Pseudotype-Based Neutralisation Assays}

To measure the neutralisation activity of this panel of sera, neutralising antibody titres were defined as endpoint two-fold seral dilutions of test samples, and the $50 \%$ inhibitory concentration $\left(\mathrm{IC}_{50}\right)$ was determined as the serum dilution resulting in a $50 \%$ reduction of a single round of infection (reporter gene-mediated signal). Values were expressed as a percentage in comparison with the signal from the cell-only control (equivalent to $100 \%$ neutralisation and/or no infection) and the signal from a pseudotype-only control (equivalent to $0 \%$ neutralisation or $100 \%$ infection).

In brief, two-fold serial dilution of serum samples, starting from 1:10, was performed in a culture medium (DMEM, 5\% FBS, 1\% PEN-STREP, 1\% L-Glutamine). The serum was mixed with SARS-CoV-2 pseudotypes in a 1:1 vol/vol ratio in a 96-well culture plate. The virus input used was $1 \times 10^{6} \mathrm{RLU} /$ well (based on the previous titration).

The serum-pseudotypes mixture was then incubated for $1 \mathrm{~h}$ at $37^{\circ} \mathrm{C}$ in a humidified atmosphere with $5 \%$ CO2. After $1 \mathrm{~h}$, HEK 293/ACE2 transfected cell suspensions $\left(1.5 \times 10^{4} \mathrm{cell} / \mathrm{mL}\right)$ were seeded into each well of flat-bottomed tissue culture plates. The plates were incubated at $37^{\circ} \mathrm{C}$ for $48-72 \mathrm{~h}$, and the neutralising antibodies were characterised on the basis of luciferase activity.

\subsection{Live Virus, Titration and Microneutralisation Assay}

The SARS-CoV-2 strain 2019-nCov/Italy-INMI1-wild-type virus was purchased from the European Virus Archive Goes Global (EVAg, Spallanzani Institute, Via Portuense, 292, 00148-00153, Rome) and propagated in Vero E6 cells. The virus was titrated in a Tissue Culture Infective Dose $50 \%$ assay (TCID50) on 96-well culture plates with 1-log serial dilution. The plates were observed daily for a total of four days for the presence of cytopathic effect (CPE). The end-point titre was calculated according to the Spearman-Karber formula [32].

The MN assay was performed as previously reported by Manenti et al. [24]. Briefly, two-fold serial dilutions of serum samples were mixed with an equal volume of viral solution containing 100 TCID50 of SARS-CoV-2. The serum-virus mixture was incubated for $1 \mathrm{~h}$ at $37^{\circ} \mathrm{C}$ in a humidified atmosphere with $5 \% \mathrm{CO}_{2}$, then passed to a VERO E6 culture plate. The plates were incubated for four days at $37^{\circ} \mathrm{C}$ in a humidified atmosphere with $5 \% \mathrm{CO}_{2}$. After the incubation time, each well of a 96-well plate was inspected by means of an inverted optical microscope to evaluate the percentage of CPE.

\subsection{Statistical Analyses}

\subsubsection{Calculation of SARS-CoV-2 Pseudotype Titres}

Pseudotype transduction titres were estimated by means of Excel ${ }^{\mathrm{TM}}$ software; the pseudotype titres obtained at each point in a range of dilution points were expressed as $R L U / m L$, and the arithmetic mean was calculated. For the analyses of pseudotype-based neutralisation assays, titres were firstly normalised, and $\mathrm{IC}_{50}$ values were calculated by a non-linear regression model (log (inhibitor) vs. normalised response-variable slope) analysis. Titres were subsequently expressed as the range of dilution in which the $\mathrm{IC}_{50}$ value lay. In order to evaluate cell infectivity, two-way analysis of variance (ANOVA) with Dunnett posttest was used to test for statistical significance ( $p>0.05$ (ns, not significant), $p \leq 0.05\left(^{*}\right), p \leq 0.01\left(^{(* *}\right), p \leq 0.001\left(^{* * *}\right)$, and $p \leq 0.0001\left(^{(* * *)}\right)$. For all statistical analyses, the GraphPad Prism version 8.4 package was used (GraphPad Software, GraphPad, 2365 Northside Dr., Suite 560, San Diego, CA 92108, USA).

2.9.2. Comparison between Live Virus Microneutralisation Titres (MNT) and Pseudotype Neutralising Titres (PNT)

The statistical analyses have been undertaken with the $\mathrm{R}$ software (version 3.6.2). Different approaches drove our statistical analyses, as shown in Figure 1. 


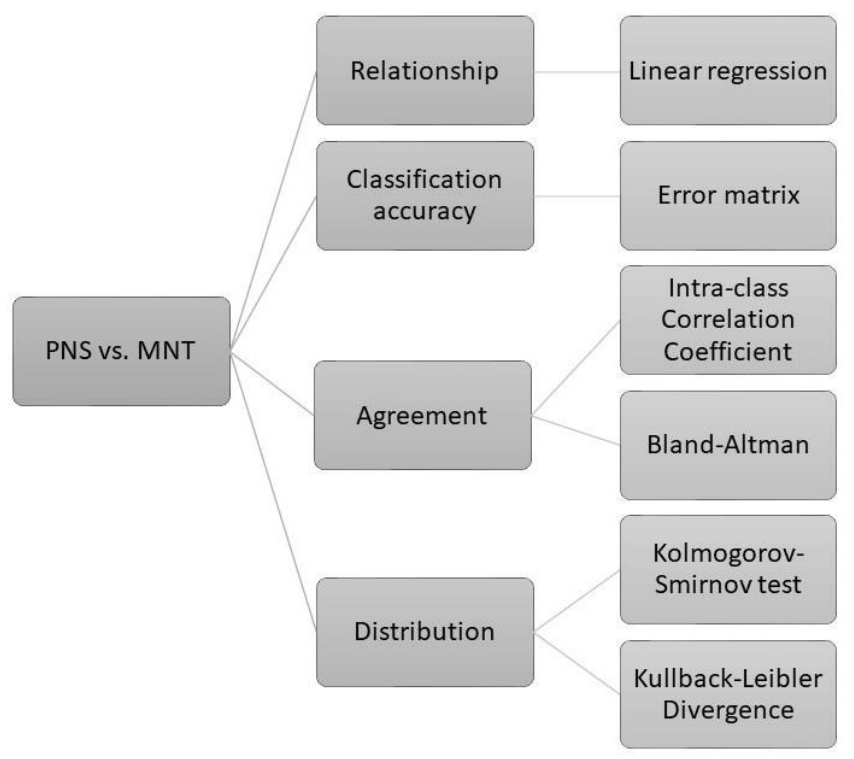

Figure 1. Flowchart of the statistical methods. Comparison between pseudotype neutralising titres (PNT) and live virus micro-neutralisation titres (MNT) was conducted via different approaches, which enabled us to elucidate the overall convergence of the PNT and MNT results.

All the titres underwent preliminary base-2 logarithmic transformation. In accordance with the classification approach, the titres greater than $\log 2(5)$ were labelled as "Positive," and otherwise as "Negative." With MNT taken as the reference ("true") results, the misclassifications were counted and displayed in an error matrix table.

A linear regression model provided a measure of the strength of the relationship between PNT and MNT. As the dependent variable, we considered the $\log 2$ of PNT, and as the independent variable, the $\log 2$ of MNT.

For the evaluation of the agreement between PNT and MNT, we used the intra-class correlation coefficient (ICC). In addition, the Bland-Altman method (BA) enabled us to search for possible systematic difference (bias) between the PNT and MNT, as well as to identify the presence of outliers. The BA evaluation mainly consists in a scatter plot of the differences between the measurements vs. their means. The 95\% limits of agreement (LOAs) were calculated around the mean of the differences. We set a maximum acceptable difference (MAD) of 0.5 times the MNT, below which the observed PNT-MNT differences were considered as not having a significant biological effect. We interpreted the differences below the MAD and within the $95 \%$ limits of agreement as interchangeable. By comparing the distributions of PNT and MNT, we got further insight into their similarity degree. Thus, we applied the Kolmogorov-Smirnov test and measured the Kullbac-Leibler divergence (KLD). The former considers the largest difference between the empirical distribution functions of the PNT and MNT tests, and the latter is an information theoretic-based value, which indicates how much information is lost when taking PNT as an approximation of MNT. The KLD was calculated as the "true" reference the MNT distribution, and normalised as follows:

$$
n K L D\left(p_{M N T} \| p_{P N T}\right)=\frac{1}{1+e^{K L D}}-\frac{1}{2}
$$

where $n K L D$ is the normalised divergence, and $p M N T$ and $p P N T$ are the distributions of $M N T$ and PNT, respectively. This normalisation restricts the divergence values in the range $[-0.5,+0.5]$, such that $n K L D=0$ if the PNT distribution perfectly reproduces the MNT distribution, while the extremes $n K L D=-0.5$ or $n K L D=0.5$ are attained if $K L D$ tends towards infinite, (positive or negative infinite, respectively). Lastly, we conducted a bootstrap test (100,000 resamples with replacement from the $M N T$ and PNT data) on the KLD statistic under the null hypothesis of $n K L D=0$. 


\section{Results}

\subsection{SARS-CoV-2 Spike Protein Expression Evaluated by Western Blotting and p24 Quantification}

SARS-CoV-2 S glycoprotein and gag-p24 in pseudotypes were characterised by immunoblot analysis and p24 ELISA, respectively.

To verify the expression of the spike protein in the SARS-CoV-2 pseudotypes, the spike was detected by Western blot; sera from convalescent SARS-CoV-2 patients, which have been shown to have a high neutralising titre in microneutralisation with a live virus, were used as the primary antibody, and goat anti-Human IgG as the secondary antibody.

SARS CoV-2 strain 2019-nCov/Italy wild-type virus (LV), which was handled in a level 3 bio-containment facility (BSL 3), was used as positive control in order to evaluate the spike glycoprotein expression, while a $\Delta$-envelope pseudotype, prepared with the same procedure, was used as a negative control.

Three different batches of pseudotypes were tested; specific bands were found for SARS-CoV-2 pseudotypes and for SARS-CoV-2 live virus, but not for the $\Delta$-envelope control (Figure 2).

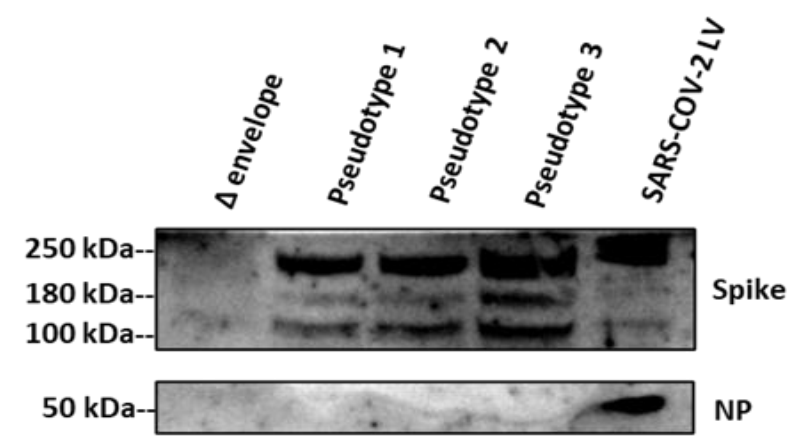

Figure 2. Incorporation of SARS-CoV-2 protein into pseudotypes. The spike protein of the particles was investigated by Western blotting. From left to right: lanes showing $\Delta$-envelope pseudotype; SARS-CoV-2 Pseudotype batch 1, batch 2, batch 3; and SARS-CoV-2 live virus (LV). The LV was used as a positive control and the $\Delta$-envelope (particles bearing no envelope protein), prepared with the same procedure, was used as a negative control. Uncleaved S protein, about $180 \mathrm{kDa}$; cleaved S protein, about $100 \mathrm{kDa}$; dimeric-trimeric $S$ protein, above $250 \mathrm{kDa}$; Nucleocapsid protein, about $50 \mathrm{kDa}$. Experiments were done twice and one is shown.

Regarding the pseudotypes, we observed three main bands: one just below $250 \mathrm{kDa}$, and the remaining two bands at $180 \mathrm{kDa}$ and $100 \mathrm{kDa}$, corresponding to the full-length and cleaved S protein, as shown in previous studies [33].

These two bands (180 kDa and $100 \mathrm{kDa})$ were barely detectable in the live virus, in which was observed one just above $250 \mathrm{kDa}$, possibly reflecting the dimeric-trimeric $\mathrm{S}$ protein (detected in the pseudotypes below $250 \mathrm{kDa}$ ), and the other band was around $50 \mathrm{kDa}$, possibly corresponding to the Nucleocapsid Protein (NP). The high glycosylation potential to which the spike is subjected during the infection differs from the spike expressed on the pseudotyped particles that do not undergo the same post-translational modifications [34]. This would explain the presence of a protein with a weight greater than $250 \mathrm{kDa}$ in the wild type virus, compared to the three isoforms with detectable molecular weight between $100 \mathrm{KDa}$ and below $250 \mathrm{kDa}$ related to the pseudotypes [33].

Moreover, the quantitative data can slightly differ when a convalescence serum sample is used instead of an antibody (e.g., monoclonal antibody), specifically directed against a defined protein's portion.

Although, in this study, the evaluation of SARS-CoV-2 pseudotype titres is based on the reporter gene expression (RLUs/mL), a number of eight different batches of SARS-CoV-2 lentiviral pseudotypes 
were also compared for the HIV-1 viral core protein p24 amount (directly correlating to the number of particles) by ELISA (values reported as pg of p24 for $\mathrm{mL}$ ).

The results showed that all batches tested consistently contained around $13-15 \mathrm{pg} / \mathrm{mL}$ of p24 gag capsid protein, corresponding approximately to a titre of $1.30 \mathrm{e}+05 \mathrm{RLUs} / \mathrm{mL}$. Similar vector infectivity was also identified for VSV-G pseudotyped vectors, around $15-16 \mathrm{pg} / \mathrm{mL}$ of p24 gag capsid protein corresponding to an approximate titre of $1.56 \mathrm{e}+05 \mathrm{RLUs} / \mathrm{mL}$, while a value of $9-10 \mathrm{pg} / \mathrm{mL}$, corresponding to a titre of $9.94 \mathrm{e}+04$, was obtained for $\Delta$-envelope pseudotypes, as shown in Figure 3 . The values obtained for the Delta envelope are slightly higher for the p24 amount compared to the RLUs. A possible explanation, as showed by Geraerts [35], is that p24 quantification by ELISA will detect cores lacking envelope glycoproteins (non-functional) as well as cores belonging to transduction competent (functional) pseudotypes, and this technique usually overestimates the functional vector titre. In fact, it also been shown that omission of the envelope plasmid during the vector production resulted in p24 being comparable with those of a normal production although with a non-detectable functional titre.

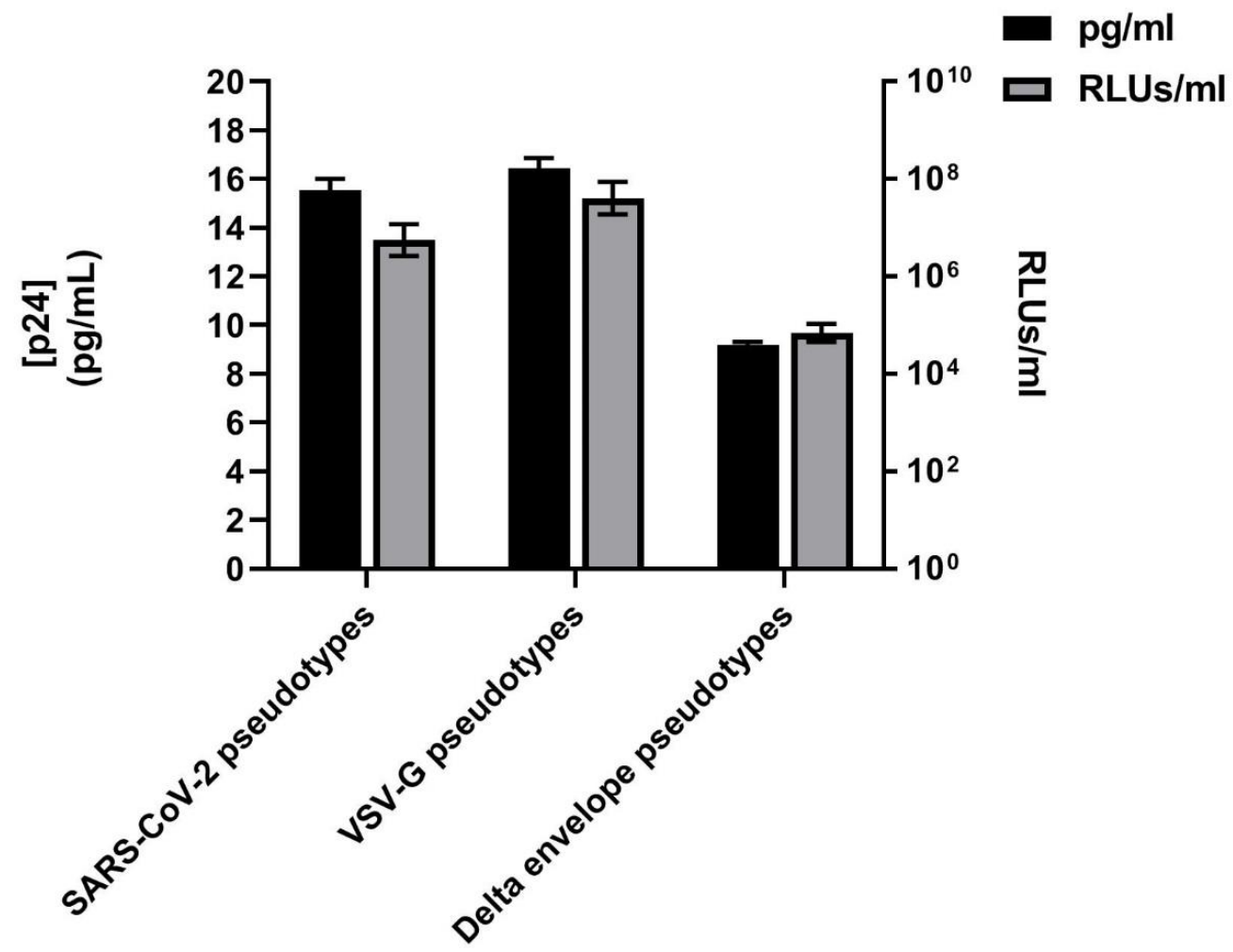

Figure 3. p24 quantification. Vector particle concentration (pg p24 protein per $\mathrm{mL}$ ) determined by $\mathrm{p} 24$ ELISA and corresponding lentiviral vector infectivity (RLUs/mL). Values expressed as the means \pm SD of independent measurements $(n=8)$.

\subsection{Susceptibility of Cell Lines Panel to SARS-CoV-2 for Pseudotype-Based Neutralisation Assays}

After the production of the SARS-CoV-2 pseudotypes, we asked which cell lines were susceptible to pseudotype-driven entry in order to have a panel of cell lines that can be used in downstream pseudotype-neutralisation assays. For this purpose, we used a panel of cell lines of human and animal origin.

Since SARS-CoV-2 live virus has been successfully isolated in Vero (African Green monkey kidney cell line), Vero E6 and Huh7 cell lines at high titres (as shown previously [24]), these were chosen for the cell tropism study. The Hep G2, MDCK and Caco cells were also included in this panel because a previous study evidenced ACE2 receptor expression, except for HEK 293T/17 [36]. However, HEK 293/17 cells have also been included as control cell line due to their high transfectability, 
and they were firstly optimised using different ACE2-expressing plasmid concentrations. Based on these preliminary results, this panel of cell lines was tested against SARS-CoV-2, VSV-G and Delta envelope pseudotypes.

As also seen in previous studies $[10,20]$, all the cell lines tested were highly susceptible to entry driven by VSV-G pseudotypes as demonstrated by titres of $10^{7}-10^{8}$ RLUs/mL (Figure 4). All the cell lines tested were also susceptible to entry by SARS-CoV-2 pseudotypes, in particular, HEK 293 ACE2/TMPRSS2-transfected cells, as demonstrated by titres of $10^{8}-10^{9}$ RLUs/mL. However, no statistical differences have been observed when SARS-CoV-2 pseudotypes have been tested against different cell lines. This comparable susceptibility can be due to the similar ACE2 expression (except for MDCK cell line as also showed by Nie et al. [20]). Moreover, co-transfection with TMPRSS2 protease can potentially level the titres obtained with different cell lines except for HEK 293/17.

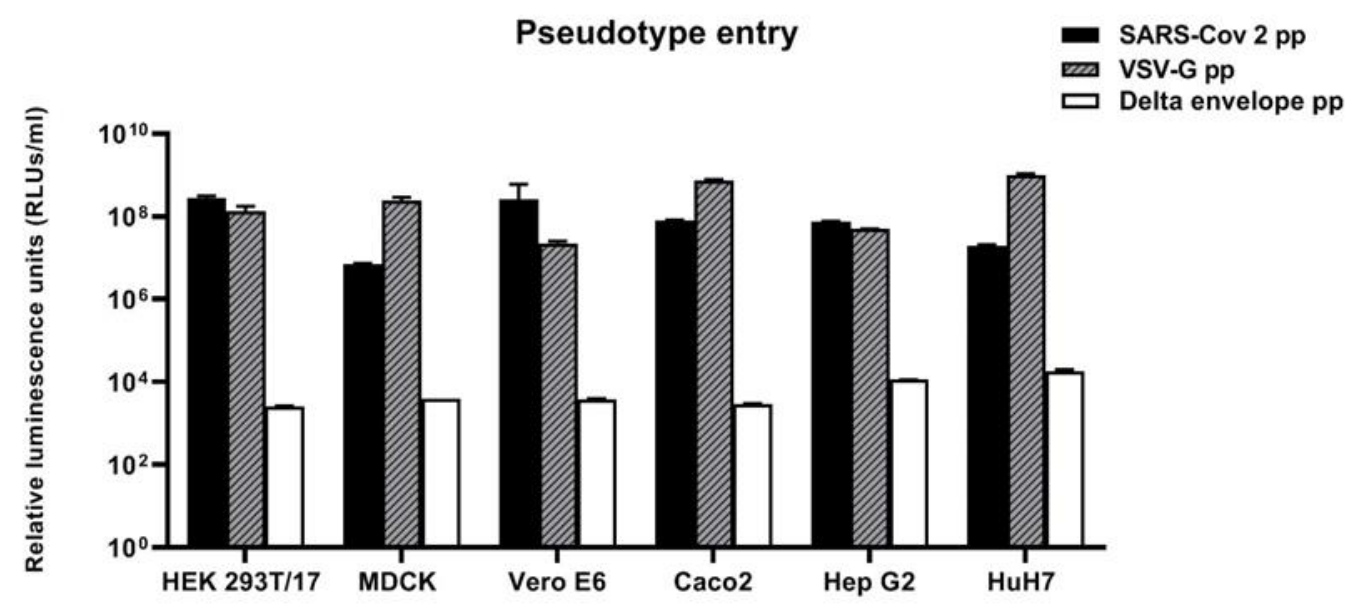

Figure 4. Susceptibility of cell lines to SARS-COV-2 driven entry. Cell lines of human and animal origin infected with $\Delta$-envelope pseudotypes, SARS-COV-2 pseudotypes and VSV-G pseudotypes. At $72 \mathrm{~h}$ post-infection, pseudotype entry was analysed by determining luciferase activity in cell lysates. Cell background without pseudotypes infection was used for normalisation. Values are expressed as the means of independent results \pm SD $(n=3)$. Two-way analysis of variance (ANOVA) test was used for statistical analysis.

As expected, when cell lines were tested with $\Delta$-envelope control (particles without envelope proteins) the transduction activity dropped drastically (4-log), corresponding to $10^{3}-10^{4}$ RLUs/mL (Figure 4).

\subsection{Correlation between Live Virus MN and Pseudotype-Based Neutralisation Assays}

As shown in Table 1, of 65 human serum samples tested, 24 proved positive for PNT, with titres ranging between 10-20 and >1280, and 28 positives for MNT, with titres ranging between 10 and 1280 (Table 2). Forty-one human samples were found negative for PNT and 37 negative for MNT. Therefore, only titres obtained for 4 sera were found to be discordant.

Table 1. Error matrix. Reliability of PNT compared to MNT in serum samples from 65 subjects. Titres greater than $\log 2(5)$ were labelled as "Positive", and otherwise as "Negative". With MNT taken as the reference (true) results, the table shows the misclassifications.

\begin{tabular}{cccc}
\hline & \multicolumn{2}{c}{ MNT } & \\
PNT & Negative & Positive & Total \\
\hline Negative & 37 & 4 & 41 \\
Positive & 0 & 24 & 24 \\
\hline Total & 37 & 28 & 65 \\
\hline
\end{tabular}


Table 2. Panel of human sera tested by live virus MN and pseudotype-based neutralisation assays. Responses against SARS-CoV-2 are expressed as antibody titres for both assays (end-point dilution).

\begin{tabular}{|c|c|c|}
\hline ID Samples & $\begin{array}{c}\text { Live Virus Micro } \\
\text { Neutralisation Titres (MNT) }\end{array}$ & $\begin{array}{c}\text { Pseudotype Neutralisation } \\
\text { Titres (PNT) }\end{array}$ \\
\hline 1 & 5 & $<10$ \\
\hline 2 & 5 & $<10$ \\
\hline 3 & 5 & $<10$ \\
\hline 4 & 5 & $<10$ \\
\hline 5 & 5 & $<10$ \\
\hline 6 & 5 & $<10$ \\
\hline 7 & 5 & $<10$ \\
\hline 8 & 5 & $<10$ \\
\hline 9 & 5 & $<10$ \\
\hline 10 & 5 & $<10$ \\
\hline 11 & 10 & $10-20$ \\
\hline 12 & 10 & $<10$ \\
\hline 13 & 10 & $<10$ \\
\hline 14 & 20 & $40-80$ \\
\hline 15 & 20 & $40-80$ \\
\hline 16 & 20 & $<10$ \\
\hline 17 & 20 & $<10$ \\
\hline 18 & 20 & $160-320$ \\
\hline 19 & 40 & $160-320$ \\
\hline 20 & 40 & $160-320$ \\
\hline 21 & 40 & $80-160$ \\
\hline 22 & 80 & $160-320$ \\
\hline 23 & 80 & $160-320$ \\
\hline 24 & 80 & $320-640$ \\
\hline 25 & 80 & $160-320$ \\
\hline 26 & 80 & $160-320$ \\
\hline 27 & 160 & $160-320$ \\
\hline 28 & 160 & $160-320$ \\
\hline 29 & 160 & $>1280$ \\
\hline 30 & 320 & $640-1280$ \\
\hline 31 & 640 & $>1280$ \\
\hline 32 & 640 & $20-40$ \\
\hline 33 & 640 & $320-640$ \\
\hline 34 & 640 & $>1280$ \\
\hline 35 & 640 & $>1280$ \\
\hline 36 & 1280 & $>1280$ \\
\hline 37 & 1280 & $>1280$ \\
\hline 38 & 1280 & $640-1280$ \\
\hline 39 & 5 & $<10$ \\
\hline 40 & 5 & $<10$ \\
\hline 41 & 5 & $<10$ \\
\hline 42 & 5 & $<10$ \\
\hline 43 & 5 & $<10$ \\
\hline 44 & 5 & $<10$ \\
\hline 45 & 5 & $<10$ \\
\hline 46 & 5 & $<10$ \\
\hline 47 & 5 & $<10$ \\
\hline 48 & 5 & $<10$ \\
\hline 49 & 5 & $<10$ \\
\hline 50 & 5 & $<10$ \\
\hline 51 & 5 & $<10$ \\
\hline 52 & 5 & $<10$ \\
\hline 53 & 5 & $<10$ \\
\hline
\end{tabular}


Table 2. Cont.

\begin{tabular}{ccc}
\hline ID Samples & $\begin{array}{c}\text { Live Virus Micro } \\
\text { Neutralisation Titres (MNT) }\end{array}$ & $\begin{array}{c}\text { Pseudotype Neutralisation } \\
\text { Titres (PNT) }\end{array}$ \\
\hline 54 & 5 & $<10$ \\
55 & 5 & $<10$ \\
56 & 5 & $<10$ \\
57 & 5 & $<10$ \\
58 & 5 & $<10$ \\
59 & 5 & $<10$ \\
60 & 5 & $<10$ \\
61 & 5 & $<10$ \\
62 & 5 & $<10$ \\
63 & 5 & $<10$ \\
64 & 5 & $<10$ \\
65 & 5 & $<10$ \\
\hline
\end{tabular}

When mABs have been tested against pseudotypes and the live virus, no neutralisation activity was observed on $\mathrm{MN}$, while an evident neutralisation profile was seen for PNT against Human Anti-IgM [37] SARS-CoV-2 spike S1 ( $\left.\mathrm{IC}_{50}>1280\right)$.

In addition, we defined the parameters of sensitivity, specificity and accuracy. From the error matrix (Table 1), we obtained the following results: accuracy $=93.8 \%(95 \%$ CI $(85.0 \%-98.3 \%))$, which was significantly higher $(p<0.0001)$ than the no-information rate $(56.9 \%)$, sensitivity $=85.7 \%(95 \% \mathrm{CI}$ $(67.3 \%-96.0 \%))$ and specificity $=100 \%(95 \%$ CI $(90.5 \%-100 \%))$.

A simple linear regression was conducted to predict the log2 PNT based on the log2 MNT data (Figure 5). The linear regression was found to be significant, F $(1,63)=344.6, p<0.0001$, with an $\mathrm{R}^{2}=0.84$. The PNT increased 1.09 for each $\log 2$ of the MNT.

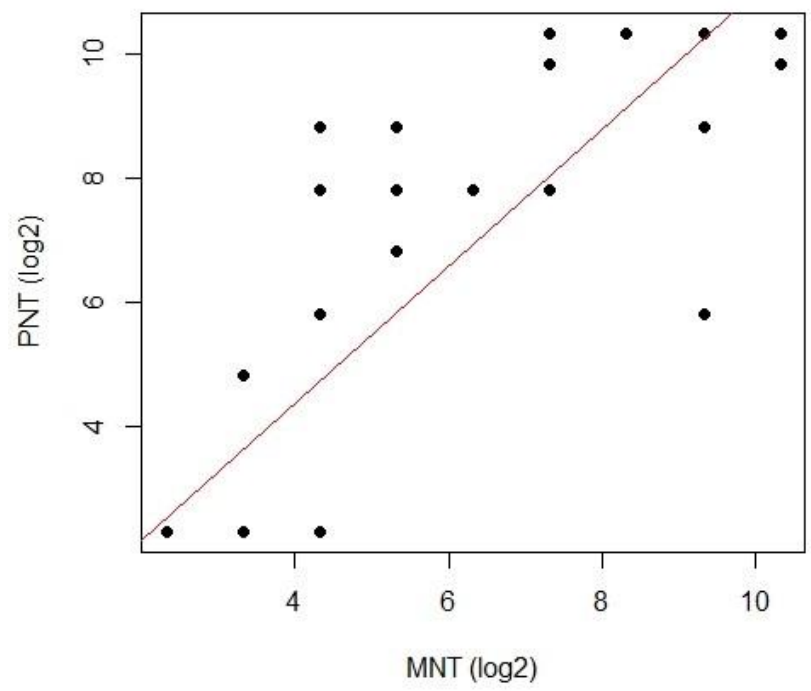

Figure 5. PNT vs. MNT relationship. The scatterplot of the MNT ( $x$-axis) and PNT (y-axis) presented a linear pattern.

To evaluate the agreement between PNT and MNT, we used the intra-class correlation coefficient (ICC). The one-way random single score ICC (Table 3) calculated between the neutralisation titres PNT and MNT was $0.872(95 \%$ CI $(0.799-0.92)), p<0.0001$. This indicated excellent agreement [38]. 
Table 3. Summary of the intra-class correlation analysis. The one-way random single score ICC calculated between the neutralisation titres PNT and MNT was 0.872 (95\% CI (0.799-0.92)), $p<0.0001$.

\begin{tabular}{cc}
\hline Model & one-way \\
Type & agreement \\
Subjects & 65 \\
Raters & 2 \\
ICC $(1)$ & 0.872 \\
CI 95\% & {$[0.799-0.92]$} \\
F-test & 14.7 \\
$p$ & $<0.0001$ \\
\hline
\end{tabular}

The Bland-Altman (BA) analysis (Figure 6) revealed the presence of a significant relationship between differences and means, which made applying a regression approach consistent [39].

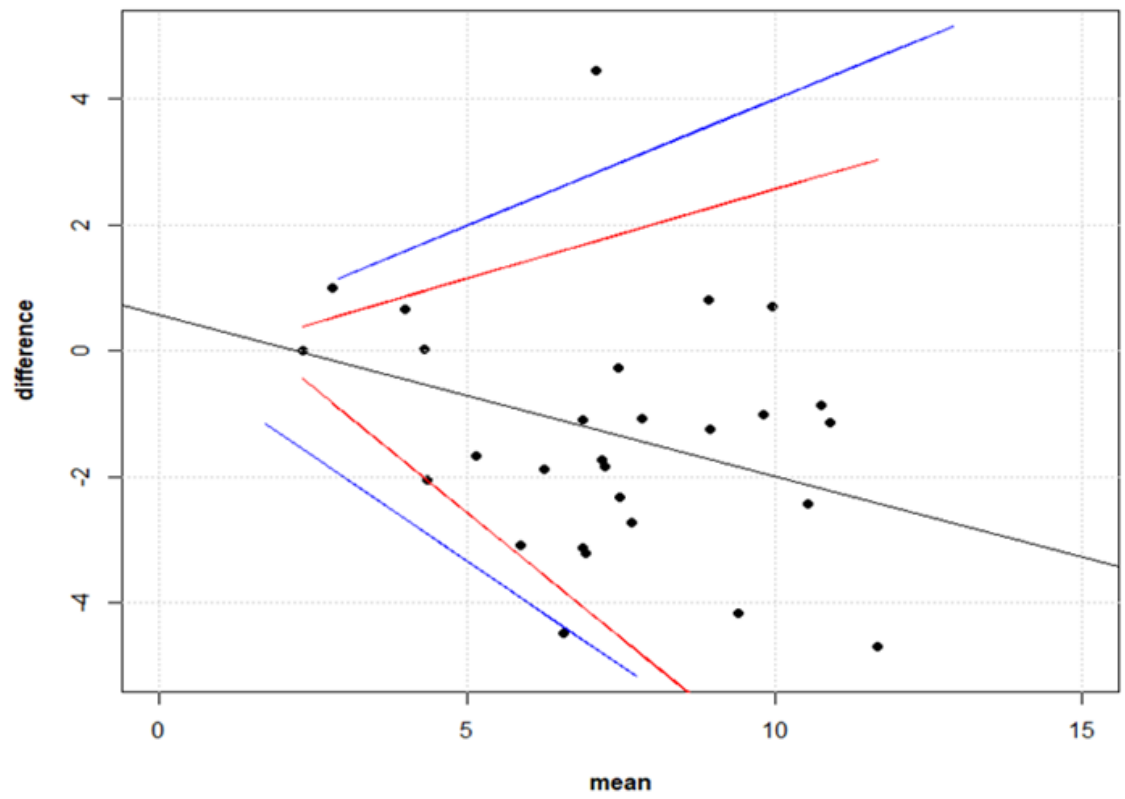

Figure 6. Bland-Altman plot. The Bland-Altman plot evaluating PNT-MNT agreement. The maximum acceptable differences (blue lines) embrace the LOAs (red lines), which makes the interpretation of the statistical results biologically plausible. We found a significant linear relationship between the differences and the means of the titres. Moreover, except for one outlier, all the differences were both biologically and statistically acceptable. In other words, there was substantial agreement between PNT and MNT.

We found that most of the data-points were within the 95\% Limit of Agreements (LOAs), while one outlier, corresponding to a means of titres equal to 6.56 (log2-units), was detected. These findings suggested that there was substantial agreement and interchangeability between PNT and MNT.

In addition, the BA method enabled us to search for possible systematic difference (bias) between the PNT and MNT, and to identify the presence of outliers.

We also concluded, on the basis of the Kolmogorov-Smirnov test, that there was not enough evidence to reject the null hypothesis of equal distributions of PNT and MNT, (KS test $=0.17, p=0.31$ ). The normalised Kullback-Leibler divergences (nKLD) between the original PNT and MNT data was equal to -0.0098 . The result of the bootstrap testing evidenced that the hypothesis of a zero nKLD between PNT and MNT was consistent with the data, $p=0.44$ (Figure 7). 


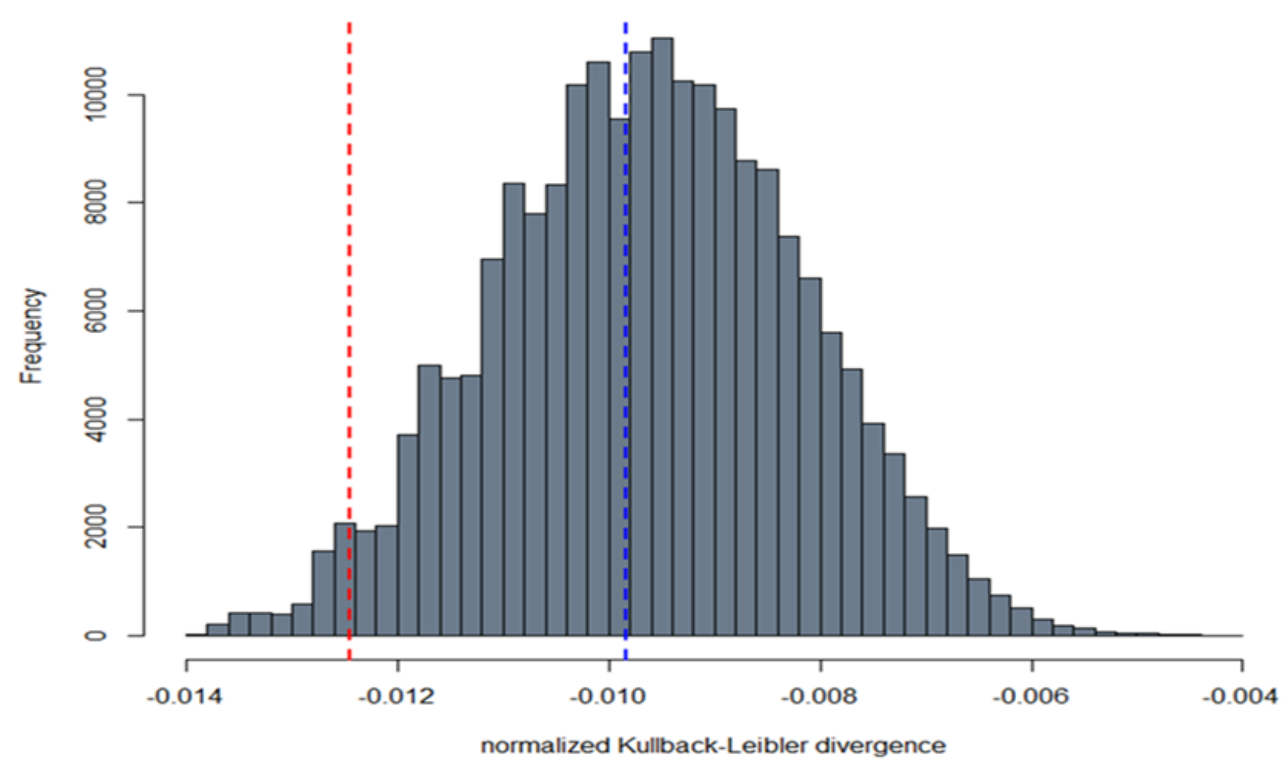

Figure 7. Bootstrap distribution of the Kullback-Leibler divergence. The histogram shows the distribution of the normalised Kullback-Leibler divergences evaluated via the bootstrap method. The nKLD between the original MNT and PNT was -0.0098 (blue dotted line). The MNT and PNT data were re-sampled with replacement 100,000 times. The red dotted line shows the 5\% lower-tail quantile (-0.0125) of the bootstrap distribution. Since the observed nKLD was lower (in absolute value) than the $5 \%$ lower-tail quantile, we concluded that the divergence was not significantly different from zero $(p$-value $=0.44)$.

\section{Discussions}

The recent emergence of the novel pathogenic SARS-Coronavirus-2 constitutes a global health emergency. As previously shown [16,21], infection with SARS-CoV-2 elicits antibodies that bind to the virus. Although several studies are still ongoing regarding the virus and the complexity of the human immune responses, neutralising antibodies are known to be strongly correlated with protection [40]. Currently, polyclonal antibodies from recovered SARS-CoV-2-infected patients have been used to treat the SARS-CoV-2 infection, but identification of SARS-CoV-2-specific neutralising mAbs is still ongoing. Once such antibodies are selected and produced, the subsequent steps will involve testing for neutralising and/or cross-neutralising activity [41], which should simplify the analysis of functional humoral immune responses.

The demand for serological testing for SARS-CoV-2 is high, as there is a need to better quantify the number of cases of COVID-19, including asymptomatic carriers [42] and patients who have recovered.

As we know, SARS-CoV-2 have a strong pathogenicity and working with the wild-type virus implies the need for level 3 bio-containment facility, according to the WHO guidelines. However, serological assays for the evaluation of neutralising activity against the SARS-CoV-2 currently require the use of isolated-live virus.

Indeed, high-throughput methods (such as ELISA) that do not require the live virus are limited by the fact that they detect total antibody binding to SARS-CoV-2 or to some of its key constituent proteins $[43,44]$. For this reason, we produced and characterised a lentiviral pseudotype system that expresses the $\mathrm{S}$ protein of SARS-CoV-2 with the same approach used by for other pathogenic coronaviruses including SARS-CoV and MERS [29,30].

This pseudotype system can be a useful tool because of its safety and versatility. Its versatility lies in the fact that the virus can be pseudotyped with different envelope proteins $[30,45,46]$. Moreover, this approach does not necessitate handling the live virus, and does not require high-level 
bio-containment facilities, as the pseudotype is devoid of virulent viral components and it is involved in a single round of replication [46].

The production of pseudotypes harbouring novel glycoproteins could permit elucidation of viral biological characteristics and a better understanding if they have potential to cause pandemics by the generation of mutants (via mutation of glycoprotein) without the risk of creating potentially dangerous viruses. It can also reflect key aspects of host cell entry and receptor binding specificity [10,33].

However, the need of additional reagents seems a requirement due to cellular receptor specificity and TMPRSS2 priming for SARS-CoV-2 pseudotypes; thus, necessitating us to optimise the batch-to-batch variations in order to reduce the variability in terms of pseudotype titres and stability.

Since previous studies have evidenced that most amino acid residues for ACE2 binding by SARS-CoV were also conserved in SARS-CoV-2 [47], we have studied different cell susceptibility to SARS-CoV-2 pseudotype entry. Understanding the entry mechanisms determined by the $S$ glycoprotein and the susceptibility of different cells (based on specific cellular receptor expression) can also provide important information to study critical process in which the S spike protein of SARS- CoV-2 is involved. Moreover, the use of multiple target cell lines is particularly valid since one of the advantages of the pseudotype-based assays is that they are deployable across different stakeholder laboratories who have access to different cell lines.

It also represents a determinant for the development and optimisation of cell-based assays and for the screening of potential entry inhibitors.

Once the SARS-CoV-2 pseudotypes have been efficiently produced, we have also developed a lentiviral pseudotype-based assay that facilitates the accurate determination of neutralising antibody responses to SARS-CoV-2 that can be paired to the more intensive and laborious $\mathrm{MN}$.

Although it is unclear as to how the display of $S$ protein on heterologous virus impacts viral entry, antibody recognition and antibody neutralisation [48], our results suggest that pseudotype-based neutralisation assays correlate well with the MN assays when testing human sera, and our findings show significant accuracy, sensitivity and specificity when both assays are compared.

When employed in the screening of vaccinated human sera and other influenza serological studies [49-52], pseudotype-based neutralisation assays have been described to be more sensitive than classical MN. The sensitivity of pseudotypes can also detect particularly low antibody responses or facilitate the antibody's recognition that cannot always be determined by conventional assays, possibly due to lower density/quantity of glycoprotein expressed on the pseudotypes [53,54]. This could explain the ability of human $\mathrm{mAB}$ IgM to recognise certain epitopes of S1 protein, as it has been seen for pseudotype-based neutralisation but not for live virus MN.

Although the model (PNT instead of MNT) returned a relatively high percentage of false-negatives, in large-scale serological testing, having a highly specific test is advantageous when a false-positive result has a great clinical impact. Indeed, it guarantees against the risk of misclassification of the true-negative samples.

Undoubtedly, for a wider use of pseudotypes, it will be necessary to take into consideration additional aspects required for standardisation such as comparison between viral vectors/expression plasmids used, optimisation of particle titres and establishment of adequate positive, negative controls and reference standards (making it more difficult to evaluate the reproducibility of different serological assays).

Moreover, as in all the cell-based assays, cell input $[55,56]$ is an important aspect in standardisation: the use of an automatic cell counter, cell viability and requirement of different proteases should be taken into account and it could be important for the consistency of the assay during different analytical sessions. Undoubtedly, a permanent cell line could be a valid alternative [18] (it would require only TMPRSS2 priming), and the generation of a cell line expressing proteases as a pseudotype producer could be investigated. 


\section{Conclusions}

Our findings suggest that SARS-CoV-2 pseudotype-based assays and the live-virus microneutralisation correlate well when employed in testing antibody responses against the novel SARS-CoV-2 virus. Undoubtedly, they would help to dissect out these diversities of immunological responses, and they can, additionally, have an important role in evaluating the neutralising antibody potency (but not necessarily predicting protection), and in testing the efficacy of potential SARS-CoV-2 vaccines.

Author Contributions: Conceptualization, I.H., E.M. (Eleonora Molesti) and A.M.; methodology, I.H., E.M. (Eleonora Molesti), E.C., L.B., A.M.; validation, I.H, and E.M. (Eleonora Molesti); formal analysis, I.H., E.M. (Eleonora Molesti) and P.P.; resources, E.M., N.JT.; data curation, P.P., I.H., E.M. (Eleonora Molesti); writing-original draft preparation, I.H. and E.M. (Eleonora Molesti); writing-review, I.H., E.M. (Eleonora Molesti), L.B., N.JT., A.M. and E.M.; visualization, I.H., E.M. (Eleonora Molesti) and P.P.; supervision and project administration, E.M. All authors have read and agreed to the published version of the manuscript.

Funding: This publication was supported by the European Virus Archive goes Global (EVAg) project, which has received funding from the European Union's Horizon 2020 research and innovation programme under grant agreement No 653316.

Acknowledgments: Thanks to Claudia Trombetta and Serena Marchi from the Department of Molecular and Developmental Medicine, University of Siena, Italy, for providing us the human serum samples from the sero-epidemiological study on SARS-CoV-2. Thanks to Prof. Valentina Bollati, from the University of Milan, for providing the sera sample from Covid-19-positive healthcare workers. Thanks to Nigel Temperton, and the Pseudotypes Unit, University of Kent, for providing the panel of plasmids used for SARS-CoV-2 pseudotype production. We thank also: Virginia Cianchi and Donata Martinuzzi for their lab support in Vismederi Research.

Conflicts of Interest: The authors declare no conflict of interest.

\section{References}

1. Chan, J.F.-W.; Yuan, S.; Kok, K.-H.; To, K.K.-W.; Chu, H.; Yang, J.; Xing, F.; Liu, J.; Yip, C.C.-Y.; Poon, R.W.-S.; et al. A familial cluster of pneumonia associated with the 2019 novel coronavirus indicating person-to-person transmission: A study of a family cluster. Lancet 2020, 395, 514-523. [CrossRef]

2. WHO 2020, Coronavirus Disease 2019 (COVID19) Situation Report 23. Coronavirus Disease 2019 (COVID-19) Situation Report-23. Available online: https:/www.who.int/docs/default-source/coronaviruse/situationreports/20200212-sitrep-23-ncov.pdf?sfvrsn=41e9fb78_4 (accessed on 10 July 2020).

3. Fehr, A.R.; Perlman, S. Coronaviruses: An Overview of Their Replication and Pathogenesis. Methods Mol. Biol. 2015, 1282, 1-23. [CrossRef] [PubMed]

4. Zhou, P.; Yang, X.-L.; Wang, X.-G.; Hu, B.; Zhang, L.; Zhang, W.; Si, H.-R.; Zhu, Y.; Li, B.; Huang, C.-L.; et al. A pneumonia outbreak associated with a new coronavirus of probable bat origin. Nature 2020, 579, 270-273. [CrossRef] [PubMed]

5. Wormser, G.P.; Aitken, C. Clinical Virology, 3rd ed.; Richman, D.D., Whitley, R.J., Hayden, F.G., Eds.; ASM Press: Washington, DC, USA, 2009; 1408p.

6. Wu, A.; Peng, Y.; Huang, B.; Ding, X.; Wang, X.; Niu, P.; Meng, J.; Zhu, Z.; Zhang, Z.; Wang, J.; et al. Genome Composition and Divergence of the Novel Coronavirus (2019-nCoV) Originating in China. Cell Host Microbe 2020, 27, 325-328. [CrossRef]

7. Li, W.; Zhang, C.; Sui, J.; Kuhn, J.H.; Moore, M.J.; Luo, S.; Wong, S.K.; Huang, I.C.; Xu, K.; Vasilieva, N.; et al. Receptor and viral determinants of SARS-coronavirus adaptation to human ACE2. EMBO J. 2005, 24, 1634-1643. [CrossRef]

8. Li, F.; Li, W.; Farzan, M.; Harrison, S.C. Structure of SARS coronavirus spike receptor-binding domain complexed with receptor. Science 2005, 309, 1864-1868. [CrossRef]

9. Zhang, H.; Penninger, J.M.; Li, Y.; Zhong, N.; Slutsky, A.S. Angiotensin-converting enzyme 2 (ACE2) as a SARS-CoV-2 receptor: Molecular mechanisms and potential therapeutic target. Intensive Care Med. 2020, 46, 586-590. [CrossRef]

10. Hoffmann, M.; Kleine-Weber, H.; Schroeder, S.; Krüger, N.; Herrler, T.; Erichsen, S.; Schiergens, T.S.; Herrler, G.; Wu, N.-H.; Nitsche, A.; et al. SARS-CoV-2 Cell Entry Depends on ACE2 and TMPRSS2 and Is Blocked by a Clinically Proven Protease Inhibitor. Cell 2020, 181, 271-280. [CrossRef] 
11. Glowacka, I.; Bertram, S.; Müller, M.A.; Allen, P.; Soilleux, E.; Pfefferle, S.; Steffen, I.; Tsegaye, T.S.; He, Y.; Gnirss, K.; et al. Evidence that TMPRSS2 activates the severe acute respiratory syndrome coronavirus spike protein for membrane fusion and reduces viral control by the humoral immune response. J. Virol. 2011, 85, 4122-4134. [CrossRef]

12. Wong, S.K.; Li, W.; Moore, M.J.; Choe, H.; Farzan, M. A 193-amino acid fragment of the SARS coronavirus S protein efficiently binds angiotensin-converting enzyme 2. J. Biol. Chem. 2004, 279, 3197-3201. [CrossRef]

13. Liu, S.; Xiao, G.; Chen, Y.; He, Y.; Niu, J.; Escalante, C.R.; Xiong, H.; Farmar, J.; Debnath, A.K.; Tien, P.; et al. Interaction between heptad repeat 1 and 2 regions in spike protein of SARS-associated coronavirus: Implications for virus fusogenic mechanism and identification of fusion inhibitors. Lancet 2004, 363, 938-947. [CrossRef]

14. Simmons, G.; Gosalia, D.N.; Rennekamp, A.J.; Reeves, J.D.; Diamond, S.L.; Bates, P. Inhibitors of cathepsin L prevent severe acute respiratory syndrome coronavirus entry. Proc. Natl. Acad. Sci. USA 2005, 102, 11876-11881. [CrossRef] [PubMed]

15. Bosch, B.J.; Martina, B.E.E.; Van Der Zee, R.; Lepault, J.; Haijema, B.J.; Versluis, C.; Heck, A.J.R.; De Groot, R.; Osterhaus, A.D.M.E.; Rottier, P.J.M. Severe acute respiratory syndrome coronavirus (SARS-CoV) infection inhibition using spike protein heptad repeat-derived peptides. Proc. Natl. Acad. Sci. USA 2004, 101, 8455-8460. [CrossRef] [PubMed]

16. Wu, F.; Wang, A.; Liu, M.; Wang, Q.; Chen, J.; Xia, S.; Ling, Y.; Zhang, Y.; Xun, J.; Lu, L.; et al. Neutralizing Antibody Responses to SARS-CoV-2 in a COVID-19 Recovered Patient Cohort and Their Implications. medRxiv 2020. [CrossRef]

17. Cheng, H.Y.; Jian, S.W.; Liu, D.P.; Ng, T.C.; Huang, W.T.; Lin, H.H. High transmissibility of COVID-19 near symptom onset. medRxiv 2020. [CrossRef]

18. Crawford, K.H.D.; Eguia, R.; Dingens, A.S.; Loes, A.N.; Malone, K.D.; Wolf, C.R.; Chu, H.Y.; Tortorici, M.A.; Veesler, D.; Murphy, M.; et al. Protocol and Reagents for Pseudotyping Lentiviral Particles with SARS-CoV-2 Spike Protein for Neutralization Assays. Viruses 2020, 12, 513. [CrossRef]

19. Millet, J.K.; Tang, T.; Nathan, L.; Jaimes, J.A.; Hsu, H.-L.; Daniel, S.; Whittaker, G.R. Production of Pseudotyped Particles to Study Highly Pathogenic Coronaviruses in a Biosafety Level 2 Setting. J. Vis. Exp. 2019, 145, e59010. [CrossRef]

20. Nie, J.; Li, Q.; Wu, J.; Zhao, C.; Hao, H.; Liu, H.; Zhang, L.; Nie, L.; Qin, H.; Wang, M.; et al. Establishment and validation of a pseudovirus neutralization assay for SARS-CoV-2. Emerg. Microbes Infect. 2020, 9, 680-686. [CrossRef]

21. Ju, B.; Zhang, Q.; Ge, X.; Wang, R.; Yu, J.; Shan, S.; Zhou, B.; Song, S.; Tang, X.; Yu, J.; et al. Potent human neutralizing antibodies elicited by SARS-CoV-2 infection. bioRxiv 2020. [CrossRef]

22. Trombetta, C.M.; Remarque, E.J.; Mortier, D.; Montomoli, E. Comparison of hemagglutination inhibition, single radial hemolysis, virus neutralization assays, and ELISA to detect antibody levels against seasonal influenza viruses. Influ. Other Respir. Viruses 2018, 12, 675-686. [CrossRef]

23. Manenti, A.; Maciola, A.K.; Trombetta, C.M.; Kistner, O.; Casa, E.; Hyseni, I.; Razzano, I.; Torelli, A.; Montomoli, E. Influenza Anti-Stalk Antibodies: Development of a New Method for the Evaluation of the Immune Responses to Universal Vaccine. Vaccines 2020, 8, 43. [CrossRef] [PubMed]

24. Manenti, A.; Maggetti, M.; Casa, E.; Martinuzzi, D.; Torelli, A.; Trombetta, C.M.; Marchi, S.; Montomoli, E. Evaluation of SARS-CoV-2 neutralizing antibodies using a CPE-based colorimetric live virus micro-neutralization assay in human serum samples. J. Med Virol. 2020. [CrossRef] [PubMed]

25. Thompson, C.; Grayson, N.; Paton, R.; Lourenço, J.; Penman, B.; Lee, L.N.; Odon, V.; Mongkolsapaya, J.; Chinnakannan, S.; Dejnirattisai, W.; et al. Neutralising antibodies to SARS coronavirus 2 in Scottish blood donors-A pilot study of the value of serology to determine population exposure. medRxiv 2020. [CrossRef]

26. Zufferey, R.; Nagy, D.; Mandel, R.J.; Naldini, L.; Trono, D. Multiply attenuated lentiviral vector achieves efficient gene delivery in vivo. Nat. Biotechnol. 1997, 15, 871-875. [CrossRef]

27. Zufferey, R.; Dull, T.; Mandel, R.J.; Bukovsky, A.; Quiroz, D.; Naldini, L.; Trono, D. Self-Inactivating Lentivirus Vector for Safe and Efficient In Vivo Gene Delivery. J. Virol. 1998, 72, 9873-9880. [CrossRef] [PubMed]

28. Böttcher, E.; Matrosovich, T.; Beyerle, M.; Klenk, H.-D.; Garten, W.; Matrosovich, M. Proteolytic Activation of Influenza Viruses by Serine Proteases TMPRSS2 and HAT from Human Airway Epithelium. J. Virol. 2006, 80, 9896-9898. [CrossRef] 
29. Temperton, N.; Chan, P.K.; Simmons, G.; Zambon, M.C.; Tedder, R.S.; Takeuchi, Y.; Weiss, R.A. Longitudinally Profiling Neutralizing Antibody Response to SARS Coronavirus with Pseudotypes. Emerg. Infect. Dis. 2005, 11, 411-416. [CrossRef] [PubMed]

30. Grehan, K.; Ferrara, F.; Temperton, N. An optimised method for the production of MERS-CoV spike expressing viral pseudotypes. MethodsX 2015, 2, 379-384. [CrossRef]

31. Stewart, S.A.; Dykxhoorn, D.M.; Palliser, D.; Mizuno, H.; Yu, E.Y.; An, N.S.; Sabatini, D.M.; Chen, I.S.; Hahn, W.C.; Sharp, P.A.; et al. Lentivirus-delivered stable gene silencing by RNAi in primary cells. RNA 2003, 9, 493-501. [CrossRef]

32. Kundi, M. One-hit models for virus inactivation studies. Antivir. Res. 1999, 41, 145-152. [CrossRef]

33. Ou, X.; Liu, Y.; Lei, X.; Li, P.; Mi, D.; Ren, L.; Guo, L.; Guo, R.; Chen, T.; Hu, J.; et al. Characterization of spike glycoprotein of SARS-CoV-2 on virus entry and its immune cross-reactivity with SARS-CoV. Nat. Commun. 2020, 11, 1-12. [CrossRef] [PubMed]

34. Shajahan, A.; Supekar, N.T.; Gleinich, A.; Azadi, P. Deducing the N- and O-glycosylation profile of the spike protein of novel coronavirus SARS-CoV-2. Glycobiology 2020. [CrossRef] [PubMed]

35. Geraerts, M.; Willems, S.; Baekelandt, V.; Debyser, Z.; Gijsbers, R. Comparison of lentiviral vector titration methods. BMC Biotechnol. 2006, 6, 34. [CrossRef] [PubMed]

36. Material not intended for publication: No. Author. Affiliation, City, State. FACS analysis, 2020.

37. Amanat, F.; Stadlbauer, D.; Strohmeier, S.; Nguyen, T.H.O.; Chromikova, V.; McMahon, M.; Jiang, K.; Arunkumar, G.A.; Jurczyszak, D.; Polanco, J.; et al. A serological assay to detect SARS-CoV-2 seroconversion in humans. Nat. Med. 2020, 26, 1033-1036. [CrossRef] [PubMed]

38. Cicchetti, D.V. Guidelines, criteria, and rules of thumb for evaluating normed and standardized assessment instruments in psychology. Psychol. Assess. 1994, 6, 284-290. [CrossRef]

39. Bland, J.M.; Altman, U.G. Measuring agreement in method comparison studies. Stat. Methods Med. Res. 1999, 8, 135-160. [CrossRef]

40. Bootz, A.; Karbach, A.; Spindler, J.; Kropff, B.; Reuter, N.; Sticht, H.; Winkler, T.H.; Britt, W.J.; Mach, M. Protective capacity of neutralizing and non-neutralizing antibodies against glycoprotein B of cytomegalovirus. PLoS Pathog. 2017, 13, e1006601. [CrossRef]

41. Jiang, S.; Hillyer, C.; Du, L. Neutralizing Antibodies against SARS-CoV-2 and Other Human Coronaviruses. Trends Immunol. 2020, 41, 355-359. [CrossRef]

42. Milani, G.P.; Montomoli, E.; Bollati, V.; Albetti, B.; Bandi, C.; Bellini, T.; Bonzini, M.; Buscaglia, M.; Cantarella, C.; Cantone, L.; et al. SARS-CoV-2 infection among asymptomatic homebound subjects in Milan, Italy. Eur. J. Intern. Med. 2020, 78, 161-163. [CrossRef]

43. Perera, R.A.; Mok, C.K.; Tsang, O.T.; Lv, H.; Ko, R.L.; Wu, N.C.; Yuan, M.; Leung, W.S.; Mc Chan, J.; Chik, T.S.; et al. Serological assays for severe acute respiratory syndrome coronavirus 2 (SARS-CoV-2), March 2020. Eurosurveillance 2020, 25, 2000421. [CrossRef]

44. Seow, J.; Graham, C.; Merrick, B.; Acors, S.; Steel, K.J.; Hemmings, O.; O’Bryne, A.; Kouphou, N.; Pickering, S.; Galao, R.; et al. Longitudinal evaluation and decline of antibody responses in SARS-CoV-2 infection. MedRxiv 2020. [CrossRef]

45. Molesti, E.; Cattoli, G.; Ferrara, F.; Böttcher-Friebertshäuser, E.; Terregino, C.; Temperton, N. The production and development of H7 Influenza virus pseudotypes for the study of humoral responses against avian viruses. J. Mol. Genet. Med. Int. J. Biomed. Res. 2013, 7, 315-320. [CrossRef]

46. Li, Q.; Liu, Q.; Huang, W.; Li, X.; Wang, Y. Current status on the development of pseudoviruses for enveloped viruses. Rev. Med. Virol. 2018, 28, e1963. [CrossRef]

47. Li, W.; Moore, M.J.; Vasilieva, N.; Sui, J.; Wong, S.K.; Berne, M.A.; Somasundaran, M.; Sullivan, J.L.; Luzuriaga, K.; Greenough, T.C.; et al. Angiotensin-converting enzyme 2 is a functional receptor for the SARS coronavirus. Nature 2003, 426, 450-454. [CrossRef]

48. Case, J.B.; Rothlauf, P.W.; Chen, R.E.; Liu, Z.; Zhao, H.; Kim, A.S.; Bloyet, L.-M.; Zeng, Q.; Tahan, S.; Droit, L.; et al. Neutralizing antibody and soluble ACE2 inhibition of a replication-competent VSV-SARS-CoV-2 and a clinical isolate of SARS-CoV-2. Cell Host Microbe 2020. [CrossRef] [PubMed]

49. Alberini, I.; Del Tordello, E.; Fasolo, A.; Temperton, N.; Galli, G.; Gentile, C.; Montomoli, E.; Hilbert, A.K.; Banzhoff, A.; Del Giudice, G.; et al. Pseudoparticle neutralization is a reliable assay to measure immunity and cross-reactivity to H5N1 influenza viruses. Vaccine 2009, 27, 5998-6003. [CrossRef] [PubMed] 
50. Molesti, E.; Wright, E.; Terregino, C.; Rahman, R.; Cattoli, G.; Temperton, N. Multiplex Evaluation of Influenza Neutralizing Antibodies with Potential Applicability to In-Field Serological Studies. J. Immunol. Res. 2014, 2014, 457932. [CrossRef] [PubMed]

51. Wang, W.; Butler, E.N.; Veguilla, V.; Vassell, R.; Thomas, J.T.; Moos, M.; Ye, Z.; Hancock, K.; Weiss, C.D. Establishment of retroviral pseudotypes with influenza hemagglutinins from H1, H3, and H5 subtypes for sensitive and specific detection of neutralizing antibodies. J. Virol. Methods 2008, 153, 111-119. [CrossRef] [PubMed]

52. Garcia, J.-M.; Lagarde, N.; Ma, E.S.; De Jong, M.D.; Peiris, J.M. Optimization and evaluation of an influenza A (H5) pseudotyped lentiviral particle-based serological assay. J. Clin. Virol. 2010, 47, 29-33. [CrossRef]

53. Wright, E.; Temperton, N.; Marston, D.A.; McElhinney, L.M.; Fooks, A.R.; Weiss, R.A. Investigating antibody neutralization of lyssaviruses using lentiviral pseudotypes: A cross-species comparison. J. Gen. Virol. 2008, 89, 2204-2213. [CrossRef]

54. Logan, N.; McMonagle, E.; Drew, A.A.; Takahashi, E.; McDonald, M.; Baron, M.; Gilbert, M.; Cleaveland, S.; Haydon, D.T.; Hosie, M.J.; et al. Efficient generation of vesicular stomatitis virus (VSV)-pseudotypes bearing morbilliviral glycoproteins and their use in quantifying virus neutralising antibodies. Vaccine 2016, 34, 814-822. [CrossRef] [PubMed]

55. The United States Pharmacopeial Convention. Design and Development of Biological Assays; The United States Pharmacopeial Convention: Rockville, MD, USA, 2010; Volume 1032, pp. 1-36.

56. The United States Pharmacopeial Convention. Biological Assay Validation; The United States Pharmacopeial Convention: Rockville, MD, USA, 2010; Volume 1033, pp. 1-25.

(C) 2020 by the authors. Licensee MDPI, Basel, Switzerland. This article is an open access article distributed under the terms and conditions of the Creative Commons Attribution (CC BY) license (http://creativecommons.org/licenses/by/4.0/). 